\title{
Wayfinding in Museums: A Cross-sectional Comparison Between 3D Serious Games and 2D Drawings as Tools for Participatory Design
}

\author{
$1^{\text {st }}$ Wolfgang Höhl \\ Department of Informatics \\ Technical University of Munich (TUM) \\ Munich, Germany \\ Wolfgang.hoehl@tum.de
}

\author{
$2^{\text {nd }}$ Farzam Kharvari \\ Dept. of $x R$-Technologies \\ Scienceviz.com - Research \\ Institute for Digital Humanities \\ Munich, Germany \\ Fzm@scienceviz.com
}

\author{
$3^{\text {rd }}$ Gudrun Klinker \\ Department of Informatics \\ Technical University of Munich (TUM) \\ Munich, Germany \\ Klinker@in.tum.de
}

\begin{abstract}
This paper investigated the impact of 3D serious games on wayfinding in public buildings. Optimal wayfinding is essential for security, economy and architectural design of public buildings. A comparative study is performed between two groups that used 2D drawings and virtual reality on the specific usecase of a museum. Following the model of Weisman, a particular questionnaire is developed. The results show "figuring out" the building was easier for the $2 \mathrm{D}$ group while wayfinding was easier for the VR group. The outcome demonstrates 3D games can be used as an effective tool in architecture for participatory and evidence-based design. Furthermore, the results show that virtual reality may be an effective tool for students to assess their designs.
\end{abstract}

Index Terms-Wayfinding, Museums, Participatory Design, Evidence-based Design, 3D Serious Games, Design Education

\section{INTRODUCTION}

While wayfinding plays a key role in different architectural projects and facilities, architects often see wayfinding as an afterthought and overlay to their buildings [1], [2]. This causes plenty of problems; a famous example is Emory University Hospital that its problems in wayfinding cost the institution $\$ 220,000$ annually [3]. Wayfinding offers various benefits, such as the sense of direction or understanding one's position in the building, to visitors of any building type [4]. Museums would benefit the most from wayfinding since dwell time and engagement play two key roles in museums. Wayfinding in museums covers functional needs such as refreshments along with ensuring visitors get the most out of their visits [5]. A positive experience boosts the reputation of museums and results in positive recommendations, reviews, and repeat visits. Furthermore, while the reduction in operating costs has turned into a major concern for museums, wayfinding systems that foster independent wayfinding will reduce costs significantly [6]. While the use of virtual applications in museums has been investigated previously [7], wayfinding as an Evidence-based

For this project we have applied for the Epic MegaGrant and the IEEE CoG 2020 Sponsor Grant. At the moment we are awaiting the final decision.

978-1-7281-4533-4/20/\$31.00 @2020 IEEE
Design (EBD) practice has not been investigated thoroughly. Therefore, this study aims to compare users' perception of wayfinding in a museum among 23 participants through a 3D serious game and 2D drawings, including plans and sections, as tools for participatory design. The outcome of this research will illustrate whether 3D games can be used as an effective tool for participatory design and as an effective perceptual tool for students.

\section{RESEARCH METHOD}

\section{A. Related Work and Designing the Questionnaire}

Architects benefit from evidence-based design (EBD) in designing museums. EBD refers to designing based on scientific research (evidence) that is usually resulted from postoccupancy evaluations as a building evaluation technique in the case of museums [8], [9]. Pre-Occupancy Evaluation is an emerging term in architecture that tries to evaluate buildings during the design process by improving client-designer communication [10]. Virtual reality and games as emerging technologies might be able to help museums achieve an improved wayfinding design since it can provide real-time evidence to designers. As a result, according to Kaplan's model of environmental cognition [11], information regarding specific locations and the spatial relationship between these locations are stored in one's mind. This provides an understanding of locations that are perceived as "different" from others by users. Accordingly, the layout configuration (plan) along with location cues, depth cues, and motion cues may impact wayfinding [12]. Accordingly, this study uses a questionnaire which was adopted and developed from an earlier study based on Kaplan's environmental cognition [11]. This study defines 3 constructs of Perceived Spatial Complexity (Describability), Anticipated Wayfinding Difficulty (Simplicity), and Remembrance (Memorability) based on the view of wayfinding as a cognitive task.

1) Describability: Describability or perceived spatial complexity refers to the students' general understanding of the spatial layout of the building. 
2) Simplicity: Similar to describability, students in this part are asked to think about addressing a specific location in the building. This part measures students' perception of the visitors' path in the building instead of the general layout.

3) Memorability: This part of the questionnaire assesses whether architectural precedents are stored in episodic memory when they are experienced according to Lawson's research [13]. In this regard, another preliminary study on architecture students showed promising results [14]. The building in this study is completely designed for fulfilling the goal of this study and students have never experienced it before since familiarity with a building affects users' responses [12]. Questions were based on a five-point Likert Scale (except Question 18 (Q18)).

The questions for Perceived Spatial Complexity (Describability) were 1) How complex was the layout of this building? 2) Do you believe you can draw a sketch of the sequence of the major spaces outlining the arrangement of the corridors and galleries inside? (You do not have to draw the actual sketch) 3) Would doing such a diagram of this building be difficult or easy? (Don't worry about your own degree of 'artistic' ability) 4) How confident would you be of the building sketch you'd have drawn? 5) My sketch would represent the arrangement of the building .... The questions for Anticipated Wayfinding Difficulty (Simplicity) were 6) How easy would it be to find one's way around a building with this layout? 7) Can you address a stranger how to circulate inside the building to find a specific part of the building 8) How accurate do you believe your address would be? 9) How easy do you believe it would be for the stranger to find the addressed part of the building? 10) How lost can a visitor become in this building in your opinion?. Finally, the questions for Remembrance (Memorability) were 11) Roughly what percentage of the total building would you say you can remember? 12) A drawn sequence of spaces by you can represent the arrangement of spaces ... 13) Do you think you'd be able to direct a stranger to galleries inside the building? 14) How confident would you be of the directions you'd give to such a stranger? 15) All things considered, do you find this building a relatively easy or a relatively difficult place to "figure out"? 16) Do you find this building a relatively easy or relatively difficult place to find your way? 17) Finding way inside the building is ... 18) includes a set of diagrams that participants should indicate which one of the diagrams best represents the order of spaces in the building based on their opinion.

\section{B. Validity and Reliability}

The questionnaire was given to a panel of experts, including 8 panelists, with 3 to 17 years of experience in architecture for content validity based on a 4-point scale. Content Validity Index at item-level (I-CVI) was 0.945 (minimum for new instruments $=0.8[15]$ ). Content Validity Index at scale level using Universal Agreement among panelists was 0.555 for the questionnaire $(\mathrm{S}-\mathrm{CVI} / \mathrm{UA}=0.555)$ which is considered excellent [16]. The Content Validity Ratio (CVR) was 0.888 which is above 0.75 and acceptable [17]. Since the nature of this study relied entirely on a project that has been devel- oped for its aim (measuring memorability), the reliability of the questionnaire was assessed using Cronbach's Alpha [18] among 31 senior students of bachelor's program (Excluding Q18 because of its special assessment type) and test-retest was not conducted. Table I shows Cronbach's Alpha, I-CVI and S-CVI/UA and CVR for the questionnaire.

TABLE I

VALIDITY AND RELIABALITY

\begin{tabular}{l|c|c|c|c|}
\hline & \multicolumn{4}{|c|}{ Statistical Analysis } \\
\cline { 2 - 5 } & $\boldsymbol{I}$-CVI & $\boldsymbol{S}$-CVII/UA & $\boldsymbol{C V R}$ & Cronbach's Alpha \\
\hline Value & $0.945^{\mathrm{a}}$ & $0.555^{\mathrm{b}}$ & $0.888^{\mathrm{c}}$ & $0.777^{\mathrm{d}}$ \\
\hline Scale: & ${ }^{\mathrm{a}} \geqslant 0.80^{\mathrm{b}} \geqslant 0.51^{\mathrm{c}} \geqslant 0.75^{\mathrm{d}} \geqslant 0.7$
\end{tabular}

\section{Participants}

For conducting this research, architecture students in the third semester of undergraduate studies were chosen since they passed major courses that were related to technical drawings, interpretation of technical drawings, and geometry. This gave them the skills of understanding technical drawings and matching drawings with $3 \mathrm{D}$ perspectives. There were 23 students in the third semester.

\section{Prototype Development}

1) Applying theories of experiencing cities to buildings: Kevin Lynch's theory indicates that there are five qualities including Paths, Edges, Districts, Nodes, and Landmarks for any given city [19]. In this study, we tried to create similar qualities in a museum (path=vistors' path, edges $=$ physical boundaries, districts $=$ galleries, nodes $=$ spaces between galleries, landmarks=uncommon memorable spaces). The museum represents a simple geometry in the plan but has a winding visitors' path. Galleries are clearly having showcases with objects in them to avoid any misinterpretation about their location (Fig. 1). The path galleries include single showcases on the walls. The red path in Fig. 2 shows the visitors' path from the entrance (where the game starts) to the exit (where the game ends by showing "Thank you for your visit" as a pop-up text).

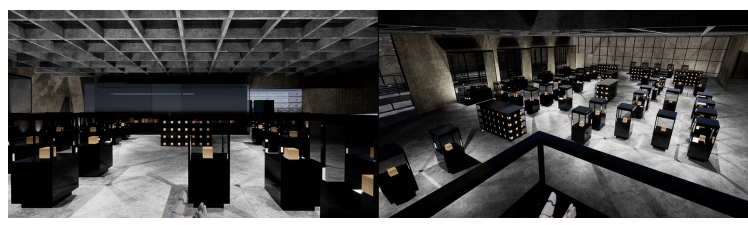

Fig. 1. Screenshots of the virtual environment

2) Time and Gaming Components: The primary gaming component in this prototype was users' ability to experience the environment as a first-person player within a specific time limit. Using a point-and-click cube-collecting game with a scoreboard distracted the users' attention from the important spatial qualities of Lynch. Therefore, we deliberately avoided to use conspicuous game elements and created an explorative non-game as a research application. Moreover, the hands of the 
player character in the game were shown to give the players a sense of orientation and scale.

3) Settings and Hardware: The prototype was developed in Unreal Engine version 4.24 for implementation on personal computers along with interactions.

\section{E. Procedure}

Researchers divided 23 participants into two groups. A group with 11 members played the 3D game for 20 minutes and the other studied technical plans for 35 minutes. The two groups were invited on different dates. After completing the game, students were given a 5-minute break while the authors were giving them directions on the questionnaire. After the briefing, the authors handed out the questionnaire. The timing of the game came from authors' playtime plus $40 \%$ extra time while more time was allocated to the $2 \mathrm{D}$ group for matching the plans and sections.
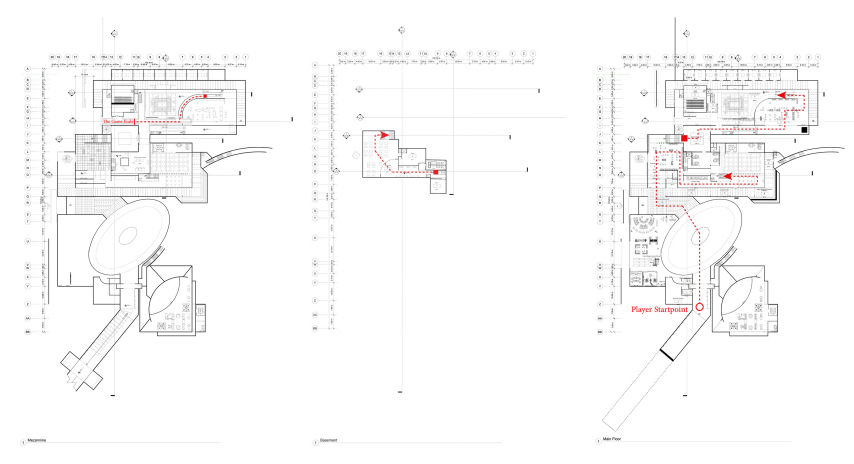

Fig. 2. Red dashed lines illustrates visitors' path in the building

\section{RESUlTS AND DISCUSSION}

\section{A. Describability}

The t-test of the two groups (Fig. 3) shows that there is a statistically significant difference between questions except for question 5 (Q5), Q11, and Q14. The t-test results illustrate Q1 has the biggest difference between the two groups in the first part. The 2D group with an average of 3.64 perceived the building as less complex. Although the 2D drawings may appear like a complex building to experts, novice students assume that the building won't be complex for users. This shows that not only students can use VR to learn about the effect of their designs but also VR is a good tool for evaluating users' experience. Similarly, the members of the 2D believed they can draw more precise sketches according to Q2 and Q3. This issue might be due to the fact that diagrams are abstract conceptual drawings that are illustrated mostly as 2D drawings. Likewise, Q4 and Q5 show they were more confident with their sequence drawings and considered them more precise although the difference between the two groups in Q5 was not statistically significant. Overall, we can see that students perceive 2D drawings as more simple and less complex in comparison to what drawings may actually be. This shows that using VR technologies in designing museums can

\begin{tabular}{|c|c|c|c|c|c|c|c|c|c|}
\hline \multicolumn{10}{|c|}{$\begin{array}{l}\text { Independent Samples Test } \\
\text { t-test for Equality of Means }\end{array}$} \\
\hline & \multirow[t]{2}{*}{ Mean } & \multirow[t]{2}{*}{$\begin{array}{l}\text { Std. } \\
\text { Deviation }\end{array}$} & \multirow[t]{2}{*}{$t$} & \multirow[t]{2}{*}{ df } & \multirow[t]{2}{*}{$\begin{array}{l}\text { Sig. (2- } \\
\text { tailed) }\end{array}$} & \multirow[t]{2}{*}{$\begin{array}{l}\text { Mean } \\
\text { Difference }\end{array}$} & \multirow[t]{2}{*}{$\begin{array}{l}\text { Std. Error } \\
\text { Difference }\end{array}$} & \multicolumn{2}{|c|}{$\begin{array}{l}95 \% \text { Confidence } \\
\text { Interval of the } \\
\text { Difference }\end{array}$} \\
\hline & & & & & & & & Lower & Upper \\
\hline & 3.64 & 0.809 & 4.336 & 21 & 0.000 & 1.553 & 0.358 & 0.808 & 2.298 \\
\hline & 2.08 & 0.900 & 4.357 & 20.995 & 0.000 & 1.553 & 0.356 & 0.812 & 2.294 \\
\hline \multirow{2}{*}{ Q2 } & 3.82 & 0.751 & 2.942 & 21 & 0.008 & 1.068 & 0.363 & 0.313 & 1.823 \\
\hline & 2.75 & 0.965 & 2.975 & 20.492 & 0.007 & 1.068 & 0.359 & 0.320 & 1.816 \\
\hline \multirow{2}{*}{ Q3 } & 3.27 & 0.647 & 2.841 & 21 & 0.010 & 0.689 & 0.243 & 0.185 & 1.194 \\
\hline & 2.58 & 0.515 & 2.812 & 19.128 & 0.011 & 0.689 & 0.245 & 0.176 & 1.202 \\
\hline \multirow{2}{*}{ Q4 } & 3.45 & 0.820 & 2.828 & 21 & 0.010 & 0.955 & 0.337 & 0.253 & 1.656 \\
\hline & 2.50 & 0.798 & 2.825 & 20.707 & 0.010 & 0.955 & 0.338 & 0.251 & 1.658 \\
\hline \multirow{2}{*}{ Q5 } & 3.18 & 0.603 & 1.963 & 21 & 0.063 & 0.515 & 0.262 & -0.031 & 1.061 \\
\hline & 2.67 & 0.651 & 1.970 & 20.996 & 0.062 & 0.515 & 0.262 & -0.029 & 1.059 \\
\hline \multirow{2}{*}{ Q6 } & 2.64 & 0.924 & -3.178 & 21 & 0.005 & -1.114 & 0.350 & -1.842 & -0.385 \\
\hline & 3.75 & 0.754 & -3.149 & 19.365 & 0.005 & -1.114 & 0.35 & -1.853 & -0.374 \\
\hline & 2.45 & 522 & -3.306 & 21 & & -0.795 & & -1.296 & -0.295 \\
\hline & 3.25 & 0.622 & -3.332 & 20.858 & 0.003 & -0.795 & 0.23 & -1.292 & -0.299 \\
\hline \multirow{2}{*}{ Q8 } & 2.64 & 0.674 & -3.452 & 21 & 0.002 & -0.864 & 0.250 & -1.384 & -0.343 \\
\hline & 3.50 & 0.522 & -3.413 & 18.843 & 0.003 & -0.864 & 0.253 & -1.394 & -0.334 \\
\hline & 2.55 & 0.522 & -3.459 & 21 & 0.002 & -0.87 & 0.252 & -1.395 & -0.347 \\
\hline & 3.42 & 0.669 & -3.498 & 20.518 & 0.002 & -0.871 & 0.249 & -1.390 & -0.352 \\
\hline \multirow{2}{*}{ Q10 } & 3.64 & 0.674 & 2.892 & 21 & 0.009 & 0.720 & 0.249 & 0.202 & 1.237 \\
\hline & 2.92 & 0.515 & 2.858 & 18.694 & 0.010 & 0.720 & 0.252 & 0.192 & 1.247 \\
\hline & 3. & 0.924 & -1.891 & 21 & & -0.7 & & -1.511 & 0.072 \\
\hline & 4.08 & 0.900 & -1.888 & 20.714 & 0.073 & -0.720 & 0.38 & -1.513 & 0.074 \\
\hline \multirow{2}{*}{ Q12 - } & 4.00 & 0.775 & 4.113 & & 0.000 & 1.333 & 0.324 & 0.659 & 2.008 \\
\hline & 2.67 & 0.778 & 4.114 & 20.845 & 0.001 & 1.333 & 0.324 & 0.659 & 2.008 \\
\hline & 3.09 & 0.539 & -2.704 & 21 & 0.013 & -0.659 & 0.244 & -1.166 & -0.152 \\
\hline & 3.75 & 0.622 & -2.722 & 20.947 & 0.013 & -0.659 & 0.242 & -1.163 & -0.155 \\
\hline \multirow{2}{*}{ Q14 } & 3.00 & 0.632 & -0.306 & 21 & 0.762 & -0.083 & 0.272 & -0.649 & 0.482 \\
\hline & 3.08 & 0.669 & -0.307 & 20.973 & 0.762 & -0.083 & 0.271 & -0.648 & 0.481 \\
\hline & 4.00 & 0.632 & 4.482 & 21 & 0.000 & 1.333 & 0.297 & 0.715 & 1.952 \\
\hline & 2.67 & 0.778 & 4.524 & 20.724 & 0.000 & 1.333 & 0.295 & 0.720 & 1.947 \\
\hline \multirow{2}{*}{ Q16 } & 3.09 & & -2.296 & 21 & 0.032 & -0.576 & 0.251 & -1.097 & -0.054 \\
\hline & 3.67 & 0.651 & -2.316 & 20.806 & 0.031 & -0.576 & 0.249 & -1.093 & -0.058 \\
\hline \multirow{2}{*}{ Q17 $\frac{\text { 2D }}{\mathrm{VR}}$} & 2.91 & 0.539 & -3.067 & 21 & 0.006 & -0.674 & 0.220 & -1.131 & -0.217 \\
\hline & 3.58 & 0.515 & -3.060 & 20.611 & 0.006 & -0.674 & 0.220 & -1.133 & -0.216 \\
\hline
\end{tabular}

Fig. 3. The comparison of two groups

be an efficient and effective tool for architects and designers to examine their concepts and designs which would result in inclusive design and realtime evidence for the design process.

\section{B. Simplicity}

Q6 shows that students in the VR group were able to find their way easier. Similarly, Q7 shows that students in the VR group could provide addresses easier. Likewise, Q8 shows that the VR group with an average of 3.5 was more confident about their ability to provide accurate addresses but students' feedback on Q9 shows that wayfinding is harder for the 2D group. The VR group believed it is more likely for a visitor to become lost in the buildings $(\mathrm{Q} 10)$.

Although these evaluations are subjective and highly relies on the ability of the 2D group to interpret 2D drawings, it shows wayfinding was easier for the VR group. However, Q10 shows that students may have struggled during wayfinding and relied on exploration but they eventually were able to find their way. On the other hand, the 2D group believed it is less likely for someone to be lost in the building according to the Q10. This might due to their ability to interpret the 2D drawings and lack of experience or the psychological effect of an easyto-understand 2D drawing.

\section{Memorability}

Although Q11 was of significant importance to this study, students' feedback cannot confirm that remembering a building 
is easier for those who experience it in VR since the t-test did not show any significant difference between the two groups. The 2D group indicated that their drawn sequences of spaces may represent the arrangement of spaces more precisely (Q12). Q13 and Q14 ask about the ability of the respondents to guide someone inside the building. Although there was not a statistically significant difference between the two groups in being confident about their provided guidance based on their feedbacks (Q14), Q13 shows that the 2D group was less confident about their ability to direct a stranger to the galleries inside the building. Q15 shows that the 2D group perceived the building as an easy-to-understand building while the VR group perceived it as hard to figure out. Q16 and Q17 ask almost the same question and show wayfinding was considered easier in the VR group.

Q18 was not included in the independent t-test analysis since it measures the ability of students to find the correct diagram of spaces. In this question, the correct answer is the second one while the first choice has an error of $25 \%$, the third and fourth choice have an error of $50 \%$, and the fifth choice has an error of $75 \%$. These percentages represent the number of wrong sequences. According to the results in Fig. 4, the 2D group had the highest percentage of correct answers (54.5\%). The 2D group also had a higher percentage of the answer with a $25 \%$ error. Although none of the groups checked the answer with a $75 \%$ error, the cumulative percentage of those who checked the answers with $50 \%$ error (options 3 and 4) was higher in the VR group (33.3\%).

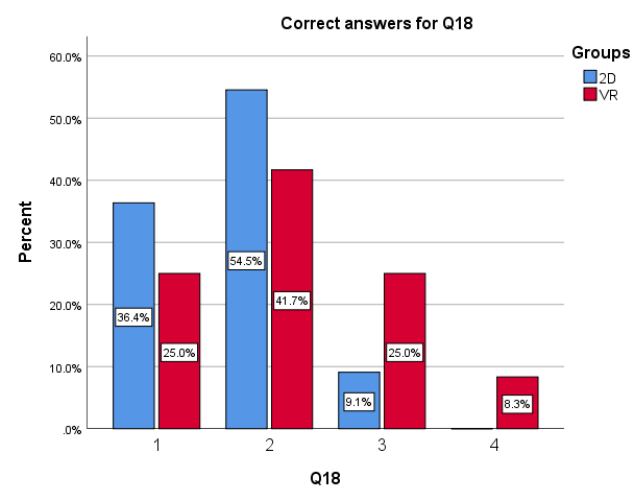

Fig. 4. Correct answers (\%)

These results show that the VR group was able to guide someone inside the building better than the $2 \mathrm{D}$ group and believed that wayfinding was easy in this building while the 2D group believed the building was easy to figure out. On the other hand, it is obvious that the 2D group figured the building out better since they provided more correct answers in Q18. This issue might be due to the fact that $2 \mathrm{D}$ drawings were more similar to the construct of the abstract spatial diagrams while the VR group had to think and come up with a 2D diagram for answering questions. On the other hand, the VR group may have found the wayfinding easy because it was a single straight path to follow while it was meandrous $2 \mathrm{D}$ drawings.

\section{CONCLUSION}

This paper investigated the impact of 3D serious games on wayfinding in a museum among architecture students through three constructs of Describability, Simplicity, and Memorability. The results showed that those who experience spatial configuration in VR may not be able to draw conceptual 2D diagrams but they can assess wayfinding easily in buildings through experiencing it. This is a valuable effect of VR since it can provide realtime evidence for architects and designers for implementation in their buildings. Furthermore, the tool can be used for novice architecture students to assess their 2D drawings or sketches. This preliminary study illustrates virtual environments can be an effective tool for participatory design and evidence-based design.

\section{REFERENCES}

[1] A. Devlin, "Wayfinding in healthcare facilities: Contributions from environmental psychology," Behav. Sci. (Basel)., vol. 4, no. 4, pp. 423436, 2014.

[2] A. S. Devlin, Transforming the doctor's office: Principles from evidencebased design. Routledge, 2014.

[3] C. Zimring, "The costs of confusion: Non-monetary and monetary costs of the Emory University hospital wayfinding system," Atlanta Georg. Inst. Technol., vol. 91, no. 2, 1990.

[4] F. Romagnoli, T. Villani, and A. Oddi, "The Environmental Contribution to Wayfinding in Museums: Enhancement and Usage by Controlling Flows and Paths," in Congress of the International Ergonomics Association, 2018, pp. 579-588.

[5] D. Gibson, The wayfinding handbook: Information design for public places. Princeton Architectural Press, 2009.

[6] H. Paddon, Redisplaying museum collections: contemporary display and interpretation in British museums. Routledge, 2016.

[7] F. Liarokapis, A. Voulodimos, N. Doulamis, and A. Doulamis, Visual Computing for Cultural Heritage. Springer, 2020.

[8] G. Baird, D. Kernohan, and H. Bruhns, Building Evaluation Techniques: A Resource Guide for Building Users. Centre for Building Performance Research, 1990.

[9] A. Engineer and S. M. B. Cordova, "Toward a human-centered approach to art museum design: Learning from volunteers' perceptions and experiences," Int. J. Architecton. Spat. Environ. Des., vol. 13, no. 3, pp. 1-12, 2019.

[10] W. Shen, X. Zhang, G. Qiping Shen, and T. Fernando, "The User Pre-Occupancy Evaluation Method in designer-client communication in early design stage: A case study," Autom. Constr., vol. 32, pp. 112-124, 2013.

[11] S. Kaplan, "Participation in the design process: A cognitive approach," in Perspectives on environment and behavior, Springer, 1977, pp. 221233.

[12] J. Weisman, "Evaluating architectural legibility: Way-finding in the built environment," Environ. Behav., vol. 13, no. 2, pp. 189-204, 1981.

[13] B. Lawson, "Schemata, gambits and precedent: some factors in design expertise," Des. Stud., vol. 25, no. 5, pp. 443-457, 2004.

[14] F. Kharvari and W. Höhl, "The Role of Serious Gaming using Virtual Reality Applications for 3D Architectural Visualization," in 2019 11th International Conference on Virtual Worlds and Games for Serious Applications (VS-Games), 2019, pp. 1-2.

[15] L. L. Davis, "Instrument review: Getting the most from a panel of experts," Appl. Nurs. Res., vol. 5, no. 4, pp. 194-197, 1992.

[16] D. F. Polit and C. T. Beck, "The content validity index: are you sure you know what's being reported? Critique and recommendations," Res. Nurs. Health, vol. 29, no. 5, pp. 489-497, 2006.

[17] C. H. Lawshe, "A quantitative approach to content validity 1," Pers. Psychol., vol. 28, no. 4, pp. 563-575, 1975.

[18] B. G. Tabachnick, L. S. Fidell, and J. B. Ullman, Using multivariate statistics, vol. 5. Pearson Boston, MA, 2007.

[19] K. Lynch, The image of the city, vol. 11. MIT press, 1960. 